\title{
Households' satisfaction with the healthcare services rendered by a ward-based outreach team in Tshwane district, Pretoria, South Africa
}

\author{
AT Masango Makgobela ${ }^{a *}$, JV Ndimande ${ }^{b}$, G Ogunbanjo ${ }^{a}$, T Bongongo ${ }^{a}$ and SN Nyalunga ${ }^{a}$ \\ ${ }^{a}$ Family Medicine and Primary Health Care Department, Sefako Makgatho Health Sciences University, Ga-Rankuwa, South Africa \\ ${ }^{b}$ Family Medicine and Primary Health Care Department, Sefako Makgatho Health Sciences University, Dr George Mukhari Academic \\ Hospital, Ga-Rankuwa, South Africa \\ *Corresponding author, email: Makgobela123@gmail.com

Introduction: Households' satisfaction is an important and commonly used indicator for measuring quality in health care. An amelioration of primary health care services at the level of households, by utilising community health workers, has led to a good healthcare system in many countries, such as Brazil. In South Africa, little is known about the satisfaction of households $(\mathrm{HH})$ regarding the healthcare services they receive from ward-based outreach teams (WBOTs). A study was undertaken to determine this phenomenon.

Methods: The study used a cross-sectional study design. Tshwane district had established 39 ward-based outreach teams at the time of the study and households were conveniently selected. Hence the study population was estimated to be 3600 . Using $99 \%$ confidence level and 5\% confidence interval, the sample size was 660 , and oversampled to 765 since all households present during the data collection were willing to be included in the survey. Data collected was captured on Microsoft Excel and analysed using SAS, version 9.2.

Results: Interviews were held with members of the families, who were willing to participate. Participants' ages ranged from 18 to 110 , mean age 53.1years (SD = 19.7). The study participants included more females $(74.0 \%)$, and $45.2 \%$ were single. The majority (89.8\%) were unemployed. Overall satisfaction was seen in 692 participants (90.7\%). Outcome of satisfaction according to sex (91.9\%), age (90.7\%) and employment $(90.8 \%)$ was not statistically significant with $p$-value $<0.05$.

Conclusions: The findings of households' satisfaction regarding the healthcare services rendered by the ward-based outreach team in Tshwane district, Pretoria, South Africa showed a high level of satisfaction from the households. This high level of satisfaction was referred to as excellent and was not associated with sex, age or employment status. A recommendation is made to all stakeholders that the ward-based outreach team programme cover all municipal wards in the country in order to raise the level of households' satisfaction with the healthcare system.

Keywords: community health workers, households, home care, healthcare service, satisfaction, ward-based outreach teams

\section{Background}

Patient satisfaction is a measure of the extent to which a patient is content with the health care which he/she receives from his/ her healthcare provider. ${ }^{1}$ Patient satisfaction is an important and commonly used indicator for measuring the quality in health care. Thus, it is a proxy but a very effective indicator to measure the success of doctors and hospitals. ' 'Household' is defined as a person or group of persons, related or unrelated, who live together and share a common source of food. ${ }^{3}$ Several countries, most notably Brazil, have improved population access to health care by focusing on the delivery of primary health care models. These healthcare services are provided at a household level by teams of professional and/or less skilled lay workers such as community health workers. ${ }^{4}$

In Taiwan, a study addressing patients' satisfaction revealed that most participants were employed females residing with partners. They were satisfied with the visit from health agents who came once a month. ${ }^{5}$ Patients' level of satisfaction was seen to increase when healthcare workers visited the family twice a month. They provided services like preventative care, e.g. providing rotavirus vaccine for children and taking care of children with diarrhoea. ${ }^{6}$

Convenience, accessibility and acceptability means that home health care is the most preferred nursing service model for most families in China. A study was done to examine the level of satisfaction in the home, concerning healthcare services residents received from primary caregivers. Results showed that there were overall satisfaction levels regarding home health care. The satisfaction was higher where the primary caregivers were older than 30 years and had a lower educational level. The services households received were: providing knowledge of illness, completing the promised tasks, and actively enquiring about patients' conditions and needs. ${ }^{7}$ Most of these services are part of the primary health care service and it is beneficial when they can be delivered to a patient's home.

In India, the quality of care in most health services was poor; hence the government started promoting community health insurance $(\mathrm{CHI})$ schemes, so that patients can access quality services. An observational study was done to measure the level of satisfaction among insured and uninsured patients in two $\mathrm{CHI}$ schemes: Action for Community Organization, Rehabilitation and Development (ACCORD) and Kadamalai Kalanjiam Vattara Sangam (KKVS), were chosen. The study found that, at both the ACCORD and KKVS schemes, there was no significant difference in the levels of satisfaction between the insured and uninsured patients. The main reasons for satisfaction were the availability of doctors, medicines and recovery by the patient. ${ }^{8}$ This is encouraging for India in the aim to provide quality care equally to private and public patients. 
As the home becomes an increasingly common venue of care for frail older adults, determining whether these consumers are satisfied with frail-care services is now recognised as an important outcome and a basic responsibility of those who provide care to this population. The Home Care Satisfaction Measure (HCSM) is commonly used in America and is an instrument based on consumer-defined notions of satisfaction. The HCSM was administered to low-income, older home care recipients. The results indicated that home care satisfaction was not related to gender, age or race but was negatively associated with physical disability, where significant social desirability effects were found. ${ }^{9}$

Community Health Workers (CHWs) provide basic public health services and medical care and are typically members of the communities in which they work. Activities of CHWs may include educating community members about health risks, promoting healthy behaviours, or linking community members with providers at formal healthcare facilities. One of the duties of CHWs is to provide promotive and preventive interventions that have the potential to improve child health. Continued observation of the satisfaction of individual receivers of this care will positively reinforce improving and strengthening health systems in any country.

Kenya embarked in a study to determine satisfaction with CHW services amongst caregivers of children under five. The service included information on child health, appointment reminders and information on community resources. Satisfaction with those services was reported by $55 \%$ of the respondents. ${ }^{10}$

A study to assess the changes of community home-based services in four African countries (Ethiopia, Malawi, South Africa and Zambia) was undertaken after the introduction of antiretroviral drugs (ARVs). Care was taken from primary health care centres to the community and focused on palliative care prior to the advent of antiretroviral therapy (ART) programmes for patients with HIV/AIDS. ${ }^{11}$ The CHWs were volunteers recruited and deployed by non-governmental organisations (NGOs) and faith-based organisations (FBOs). No further studies were done to assess the satisfaction of community members with the programmes for patients with HIV/AIDS.

In South Africa, a study regarding satisfaction was done amongn households, concentrating on their satisfaction during the last visit to a healthcare facility. The majority $(88,5 \%)$ of households, who were more satisfied, were visiting their usual healthcare provider. The interest of this study was to investigate satisfaction of patients with the health system (facility), while relaxed at their homes. ${ }^{12}$ Nearly 7 in every $10(69,3 \%)$ households reported that they went to public hospitals as their first point of access when household members fell ill or were injured. Most households (93, $5 \%)$ went to the nearest facility of its kind. The patients who preferred to travel further to access health facilities complained that long waiting periods are a reason for securing services beyond their normal catchment areas. ${ }^{13}$ The study did not focus on satisfaction regarding health services they received in their homes but from the facility they visited.

$\mathrm{CHWs}$ are now present in almost all provinces in South Africa, with the aim of reaching almost every person in the community. The ward-based outreach team (WBOT) as a component of National Health Insurance (NHI) uses $\mathrm{CHWs}$ to visit households allocated to them. ${ }^{14}$ The purpose of the team was to visit families in the community to assess any type of problem present. CHWs have to educate a household and when diseases are found, inform the households what to do; they should also promote healthy living and advice on referrals where a need is identified. Basic health care can be extended to a group of people that previously had almost no access to public health care centres. ${ }^{15}$ In South Africa little is known about the satisfaction of households with the healthcare services they receive from a WBOT. This study aimed to establish the extent to which households were satisfied with the services rendered by outreach teams.

\section{Methods}

\section{Study area and design}

This was a cross-sectional study of the households visited by CHWs in all seven sub-districts of the Tshwane health district. There are 105 wards in Tshwane but only 65 wards were covered by WBOTs during the survey. ${ }^{16}$

\section{Study population and sampling procedure}

Tshwane district had a population of 3089314 according to Statistics South Africa 2014.The district was implementing PHC reengineering initiatives and had established 39 ward-based outreach teams at the time of the study in $2015 .{ }^{17}$ Hence the study population for households was estimated to be approximately 36000 . Using a $99 \%$ confidence level and $5 \%$ confidence interval on the sample calculator, the sample size was 660; we oversampled to 765 since all household members, 18 years and older, found in the house during data collection and willing to participate were included in the sample. Participants were recruited by convenience. A self-administered questionnaire was used though some participants were assisted by the field workers.

\section{Data collection}

The researchers used a structured questionnaire, which was in three common spoken languages in Tshwane municipality: English, se-Tswana and isi-Zulu. A professional translator translated and back-translated the questionnaire for validity. This structured questionnaire was compiled by the researcher and included demographics and questions regarding the satisfaction of households with the services rendered by the WBOT. It was prior piloted in a few areas that were not included in the survey, to avoid contamination of data. The pilot study resulted in appropriate modification of the questionnaire used. We trained 15 unemployed people to become our field workers and they collected data from October 12, 2015 to November 3, 2015 and also helped the participants to complete the questionnaire.

\section{Data analysis}

Data collected were captured on Microsoft Excel 2010 (Microsoft Corp, Redmond, WA, USA) and analysed using SAS, version 9.2 (SAS Institute, Cary, NC, USA). The analysis was done with the assistance of a bio-statistician. Descriptive statistics was used to determine mean and median. A chi-square test was applied for bivariate calculations. A $p$-value less than 0.05 was considered significant when comparing variables. Results are presented in tables that contain frequencies and percentages.

\section{Ethical consideration}

The study received ethics approval from the Sefako Makgato Health Sciences Research Ethics Committee, SMUREC/114/ 2015: IR. In addition, the Tshwane District Research Committee provided permission to conduct the study in selected district health facilities (TRC Project Number: 44/2015). Anonymity and confidentiality were maintained throughout the research process and consent forms were signed by every participant. 
Participants were informed about their right to withdraw from the study at any time if they felt the need to do so.

\section{Results}

\section{Baseline characteristics: Table 1}

A total of 765 households formed the study sample. For age, data were available for 764 participants, with the mean age 53.1 years $(S D=19.7)$, ranging from a minimum of 18 years to a maximum of 110 years. Most participants were between 60 and79 years old. The majority were female $(565 / 764 ; 74.0 \%)$ and of 763 participants, 345(45.2\%) were single. Most of the participants, 686/764 (89.8\%) were unemployed and 388/762 $(50.9 \%)$ received a government grant.

Households' satisfaction with the services of the WBOT: Table 2 To assess the households' satisfaction with the services offered by the WBOT, questions about satisfaction with four possible answers were asked. The participants expressed satisfaction by choosing the best option from: poor, good, excellent or not sure.

As seen in Table 2, the majority of households surveyed expressed satisfaction with the services of the WBOT. This satisfaction was excellent and expressed by 699 (91.6\%) participants, some of whom $(679,89.0 \%)$ also expressed good handling of their follow-up. Participants were content with medical information provided by members of the WBOT $678(88.7 \%)$ and happy with the way the referrals were handled $(655,86.0 \%)$. Overall satisfaction was expressed by 692 (90.7\%) participants and was referred to as excellent.

Table 1: Baseline characteristics

\begin{tabular}{lcc}
\hline Variables & $<20$ years & $\begin{array}{c}\text { Frequencies and } \\
\text { percentages }\end{array}$ \\
\hline Age $(n=764):$ & $14(1.8)$ \\
& $20-39$ years & $217(28.4)$ \\
& $40-59$ years & $204(26.7)$ \\
& $60-79$ years & $261(34.1)$ \\
\hline Sex $(n=764):$ & 80 years & $68(8.9)$ \\
\hline Employed $(n=764):$ & Male & $199(26.1 \%)$ \\
& Female & $565(74 \%)$ \\
\hline Pensioner $(n=762):$ & Yes & $78(10.2 \%)$ \\
& No & $686(89.8 \%)$ \\
\hline Marital status & Yes & $388(50.9 \%)$ \\
$(n=763):$ & No & $374(49.1 \%)$ \\
& Single & $345(45.2 \%)$ \\
& Married & $266(34.9 \%)$ \\
& Widow & $32(4.2 \%)$ \\
\hline
\end{tabular}

Comparison of households' satisfaction by sex: Table 3 Comparing the satisfaction of households with the sex (male/ female), using a chi-square test, no statistical significance was found between the two variables since $p=0.83$ ( $p$-value $>0.05$ ).

\section{Comparison of households' satisfaction by age: Table 4}

From the mean age (53), two groups were formed: participants younger than 53 years and those equal to and older than 53 . The chi-square test showed no statistical significance between the two groups, comparing the households' satisfaction. The $p$-value was 0.52 (greater than 0.05).

\section{Comparison of households' satisfaction by employment:} Table 5

The majority of household members were unemployed (686/ $764,89.8 \%)$. Households' satisfaction was compared by employment and was not statistically significant since the $p$-value was 0.36 (greater than 0.05 ).

\section{Discussion}

Findings from the current survey showed an exceptional satisfaction $(692,90.7 \%)$ with services rendered by the ward-based

Table 3: Comparison of patient satisfaction by sex

\begin{tabular}{lccc}
\hline Sex & $\begin{array}{c}\text { Satisfied: cell } \\
\text { total (expected } \\
\text { cell total), } \boldsymbol{n}(\%)\end{array}$ & $\begin{array}{c}\text { Not satisfied: cell } \\
\text { total (expected } \\
\text { cell total), } \boldsymbol{n}(\%)\end{array}$ & $\begin{array}{c}\text { Marginal } \\
\text { row total, } \boldsymbol{n} \\
(\%)\end{array}$ \\
\hline Male & $183(183,71)$ & $17(16.29)$ & $200(26.3)$ \\
Female & $516(515.29)$ & $45(45.71)$ & $561(73.7)$ \\
Total & $699(91.9)$ & $62(8.1)$ & $761(100.0)$ \\
\hline
\end{tabular}

Table 4: Comparison of patient satisfaction by age

\begin{tabular}{lccc}
\hline Ages & $\begin{array}{c}\text { Satisfied: cell } \\
\text { total (expected } \\
\text { cell total), } \boldsymbol{n}(\%)\end{array}$ & $\begin{array}{c}\text { Not satisfied: cell } \\
\text { total (expected } \\
\text { cell total), } \boldsymbol{n}(\%)\end{array}$ & $\begin{array}{c}\text { Marginal } \\
\text { row total, } \boldsymbol{n} \\
(\%)\end{array}$ \\
\hline$<\mathbf{5 3}$ & $337(329.22)$ & $26(33.78)$ & 363 \\
$>=53$ & $355(362.78)$ & $45(37.22)$ & 400 \\
Total & $692(90.7)$ & $71(9.3)$ & $763(100)$ \\
\hline
\end{tabular}

Table 5: Comparison of households' satisfaction by employment

\begin{tabular}{lccc}
\hline Employment & $\begin{array}{c}\text { Satisfied: cell } \\
\text { total } \\
\text { (expected cell } \\
\text { total), } \boldsymbol{n}(\%)\end{array}$ & $\begin{array}{c}\text { Not satisfied: } \\
\text { cell total } \\
\text { (expected cell } \\
\text { total), } \boldsymbol{n}(\%)\end{array}$ & $\begin{array}{c}\text { Marginal } \\
\text { row total, } \boldsymbol{n} \\
(\%)\end{array}$ \\
\hline Yes & $74(71.76)$ & $5(7.24)$ & 79 \\
No & $620(62.24)$ & $65(62.76)$ & 685 \\
Total & $694(90.8)$ & $70(9.2)$ & $764(100)$ \\
\hline
\end{tabular}

Table 2: Household satisfaction with the services of the ward-based outreach team

\begin{tabular}{|c|c|c|c|c|}
\hline Question & Poor & Good & Excellent & Not sure \\
\hline How would rate your interaction with the WBOT members? $(n=763)$ & $7(0.9 \%)$ & $54(7.1 \%)$ & $699(91.6 \%)$ & $3(0.4 \%)$ \\
\hline How would you rate the follow-up(s) of your health problem (s) by the WBOT members? $(n=763)$ & $11(1.4 \%)$ & $65(8.5 \%)$ & $679(89.0 \%)$ & $8(1.2 \%)$ \\
\hline $\begin{array}{l}\text { How would you rate the information and the medical education that have been provided to you } \\
\text { by the WBOT members? }(n=763)\end{array}$ & $13(1.7 \%)$ & $69(9.1 \%)$ & $678(88.7 \%)$ & $3(0.4 \%)$ \\
\hline $\begin{array}{l}\text { How would you rate the referral of patients (to clinics or hospitals) initiated by WBOT members? ( } n= \\
\text { 762) }\end{array}$ & $8(1.1 \%)$ & $67(8.8 \%)$ & $655(86.0 \%)$ & $33(4.2 \%)$ \\
\hline How would you rate the overall services of the WBOT members? $(n=763)$ & $9(1.2 \%)$ & $61(8.0 \%)$ & $692(90.7 \%)$ & $1(0.1 \%)$ \\
\hline
\end{tabular}


outreach programme in Tshwane district, Pretoria. This excellent outcome was also noted in the 2011 study conducted in Taiwan. There, female participants were ready to raise their satisfaction levels provided that visits to the communities or homes by community health workers took place more than once a month. ${ }^{5}$ In Brazil, as a strong health indicator, satisfaction was expressed by the participants while assessing the influencing factors on Brazil's national Family Health Programme. The Tshwane district survey concluded that more needed to be done to further increase satisfaction with service from the WBOT, as a health indicator. ${ }^{6}$

A comparative study on satisfaction between insured and uninsured participants in India showed no statistical significance between the two groups. This satisfaction in both groups was the result of the availability of medical doctors and medications. ${ }^{8}$ In contrast, the Tshwane survey showed that satisfaction was obtained without the support of medical doctors or medication. Community health workers are alone on the ground and do not distribute medication.

A qualitative study addressing home care satisfaction measures in America (USA) found that a certain number of variables such as gender, age and race were not associated with satisfaction with care. ${ }^{9}$ The same observation was noted in the Tshwane survey whereby sex and age as well as employment were not associated with the excellent satisfaction obtained.

In Kirinyaga County, Kenya, the care given to children younger than five in their homes was assessed for satisfaction. Since these children could not respond, caregivers reported on five given items. The overall assessment of satisfaction was 55\%, contrary to the Tshwane survey that concentrated on adult participants and showed a higher level of satisfaction than the Kenya study. Except for this aspect of the beneficiaries of care, both surveys concluded that more has to be done in terms of involving all age groups while targeting an increased level of satisfaction.

The national health care survey, conducted in South Africa in 2010, showed $88.5 \%$ satisfaction with health care from participants. The level of satisfaction was based on participants' last clinic visit (both public and private). Although a high level of satisfaction was the overall result, the survey showed a low level of satisfaction among Black and low-income participants, while White and high-income participants had a high level of satisfaction. ${ }^{12}$ This high level of satisfaction (90.7\%) was also noted in the Tshwane survey. Nevertheless, participants were not grouped on the basis of race or economic status as done in the 2010 survey. The satisfaction noted in the 2010 survey was based on the participants' last visit to their health providers while the current (or Tshwane) survey was centred on all visits done by the community health workers to the participants' homes.

\section{Conclusion and recommendation}

The findings of households' satisfaction regarding the healthcare services rendered by the ward-based outreach team in the Tshwane district, Pretoria, South Africa showed a high level of satisfaction from the households. This high level of satisfaction was referred to as excellent. This excellent level of satisfaction was not associated with sex, age or employment status.

A recommendation is made to all stakeholders that the wardbased outreach team programme should cover all municipal wards in South Africa, in order to raise the level of households' satisfaction with the healthcare system.

\section{Strengths and weaknesses}

The study strength was increased by reducing information bias by oversampling. These are primary data collected from the Tshwane households. Most households gave favourable answers; it is possible that they feared that they may lose the service.

Acknowledgments - The researchers would like to thank the Tshwane District of Health for the funding and Prof. I Govender for excellent import to the article.

Disclosure statement - No potential conflict of interest was reported by the authors.

\section{References}

1. Farley $\mathrm{H}$, Enguidanos ER, Coletti CM, et al. Patient satisfaction surveys and quality of care: an information paper. Ann Emerg Med. 2014;64:351-357.

2. Prakash B. Patient satisfaction. J Cutan A Esthet Surg. 2010;3(3):151155.

3. Tiziana L, Ernestina C, Randall S. Did you sleep here last night? The impact of the household definition in sample surveys: a Tanzanian case study. European Population Conference, 2010 September 3-5; Vienna. (LSE Research Online; July 2011)

4. Rocha R, Soares RR. Evaluating the impact of community-based health interventions: evidence from Brazil's family health program. Health Econ. 2010;19(S1):126-158.

5. Shu-Ping W, Shou-Chuan S, Shu-Chuan L, et al. Primary caregivers satisfaction and its related factors in home health care services. Taiwan society of geriatric emergency \& critical care medicine. Int J Gerontol. 2011;5:107-111.

6. Mues KE, Resende JC, dos Santos OC, et al. User satisfaction with the family health program in vespasiano, Minas Gerais, Brazil. Rev Panam Salud Publica. 2012;31(6):454-460.

7. Sampaio LFR. The Brazilian health system: highlighting the primary health care reform. Ital J Public Health. 2010;7(4):359-368.

8. Devadasan N, Criel B, Van Damme W, et al. Community health insurance schemes \& patient satisfaction. Indian J Med. Res. 2011;133:40-49.

9. Scott MG, Kevin S, Sharon T, et al. The home care satisfaction measure: a client-cantered approach to assessing the satisfaction of frail older adults with home care services. GSA. 2000;55(5): S259-S270.

10. Kagwanja NN, Muthami L, Ng'ang'a Z. Utilization and satisfaction with community health worker services amongst caregivers of children under five in Mwea West, Kirinyaga County. IJSBAR. 2014;15:2.

11. Aantjes C, Quinlan T, Bunders J. Integration of community home based care programmes within national primary health care revitalisation strategies in Ethiopia, Malawi, South-Africa and Zambia: a comparative assessment. Global Health. 2014;10:239.

12. Kathryn HJ, Takahiro H. Satisfaction with healthcare services in South Africa: results of the national 2010 general household survey. Pan Afr Med J. 2014;18:172.

13. Health Systems Trust. South African health review 2013/14. [cited 2017 November 12]. Available from http://www.hst.org.za/ publications/south-african-health-review-2013/14

14. Kinkel H-F, Marcus T, Memon S, et al. Community oriented primary care in Tshwane District, South Africa: assessing the first phase of implementation. PHCFM. 2013;5:1.

15. Naidoo S. The South African national health insurance: a revolution in health-care delivery! J Public Health. 2012;34(1):149-150.

16. South Africa. National health act, 2003: policy on national health insurance. Government Notice No. 657. Pretoria: Government Printers, 2011.

17. General Household Surveys, 2014. Statistics South Africa. [cited 2017 June 12]. Available from https://www.statssa.gov.za>po3182014 